\title{
VIDA Y MUERTE EN LAS EMBARCACIONES CASTELLANAS ENTRE LOS SIGLOS XIII Y XV. UNA APROXIMACIÓN DESDE FUENTES LEGALES Y CRONÍSTICAS
}

\author{
MANuel Flores DíAz ${ }^{1}$ \\ Universidad Complutense de Madrid
}

Recibido: 27 de octubre de 2020

Aceptado: 10 de abril de 2021

\begin{abstract}
Resumen
Pese a que los estudios históricos sobre la marina y la navegación en la Edad Media en general y en Castilla en particular han dado un gran salto, no sólo cuantitativo, sino también cualitativo, los estudios relacionados con las condiciones de vida y las mentalidades del personal embarcado no parecen haber tenido el mismo interés. Aquí presentamos algunos aspectos, pinceladas extraídas de fuentes legales y cronísticas. Las fuentes legales nos ofrecen una vía de aproximación a las condiciones de vida en embarcaciones mercantes. Las crónicas ofrecen información sobre los peligros derivados de la acción directa de combate en la mar, la influencia de las condiciones meteorológicas, así como relacionada con el reclutamiento y suministros del personal embarcado.
\end{abstract}

\section{Palabras clave}

Castilla, navegación, climatología, alimentación, muerte.

\begin{abstract}
Despite the fact that historical studies on the navy and navigation in the Middle Ages in general and in Castile in particular have taken a great leap, not only quantitatively but also qualitatively, studies related to the living conditions and mentalities of personnel shipped do not seem to have had the same interest. Here we present some aspects, brushstrokes drawn from legal and chronological sources. Legal sources offer us a way to approach living conditions on merchant ships. The chronicles offer information on the dangers derived from direct combat action at sea, the influence of meteorological conditions, as well as related to the recruitment and supplies of the embarked personnel.
\end{abstract}

\section{Key words}

Castile, sailing, wheather, food, death.

\section{Zusammenfassung}

Trotz der Tatsache, dass die historischen Studien über die Marine und die Schifffahrt im Mittelalter im Allgemeinen und in Kastilien im Besonderen nicht nur quantitativ, sondern auch qualitativ einen großen Sprung nach vorn gemacht haben, jedoch die Studien, die sich auf die Lebensbedingungen und Mentalitäten des Personals an Bord beziehen, nicht das gleiche Interesse gehabt zu haben. Hier präsentieren wir einige Aspekte,Details aus juristischen und chronistischen Quellen. Die Rechtsquellen

1 Doctor en Historia por la Universidad Complutense de Madrid. Correo electrónico: manoloflores@, vodafone.es. ORCID: https://orcid.org/0000-0002-8200-5643. 
bieten uns eine Möglichkeit, uns die Lebensbedingungen auf Handelsschiffen besser nachempfinden zu können. Die Chroniken bieten Informationen über die Gefahren, die sich aus direkten Kampfeinsätzen auf See ergeben, über den Einfluss der Wetterbedingungen, sowie im Zusammenhang mit der Rekrutierung und Versorgung des Personals an Bord.

\section{Schlüsselwörter}

Kastilien, Navigation, Wetter, Essen, Tod.

\section{Introducción y reflexión metodológica}

En la historiografía marítima medieval, tanto de las actividades pacíficas (comercio, pesca...), como violentas (guerra, piratería...), en el ámbito geográfico de la Corona de Castilla, con la lectura de las fuentes, principalmente crónicas, llama la atención un aspecto que, en mi modesta opinión, muchas veces parece que perdemos de perspectiva al encarar una investigación histórica. Me refiero a las personas que hicieron posible dicha historia y en concreto a quienes hicieron posible la historia naval de Castilla. Específicamente echo de menos el acercamiento científico a los aspectos relacionados con su vida cotidiana. Acercamiento que sí es amplio para otros ámbitos geográficos, especialmente mediterráneos, tanto italianos, del sur de Francia o de la Corona de Aragón ${ }^{2}$. En los estudios históricos en general, pero especialmente en los últimos quince años, se ha producido una eclosión, también en los relacionados con la marina de Castilla. Por centrarnos en una faceta, la de la perspectiva bélica, destacan las aportaciones de José Luis Casado Soto, así como especialmente las de Aznar Vallejo y los historiadores que bajo su ejemplo siguen trabajando en el tema. Fuera de España el tema también ha suscitado interés, un tanto indirecto, con, por ejemplo, los trabajos de Joseph F. O Callaghan. Por si fuera poco, en los últimos años se han leído y posteriormente publicado como libro dos tesis doctorales sobre el tema. Una de García de Castro en la Universidad de Valladolid y otra de Flores Díaz en la Universidad Complutense de Madrid³.

\footnotetext{
Por ejemplo, TANGHeroni "La vita a bordeo delle navi” pp. 155-187; DufourcQ, La vie quotidienne dans les ports méditerranées au Moyen Age: Provence, Languedoc, Catalogne o García Sanz y Coll Juliana, Galeres mercants catalanes dels segles XIV $i \mathrm{XV}$.

3 Casado Soto, "Guerra naval, táctica, logística y estrategia" en García Ballesteros (dir.) Historia de la Ciencia y la Técnica en la Corona de Castilla II, vol. 2, Edad Media, pp. 567-588; Aznar Vallejo, "La guerra naval en Castilla en la Baja Edad Media" pp. 167-192. Como indica el autor en un trabajo compartido con Roberto J. González Zalacaín, hay un grupo de trabajo consolidado desde hace años en la Universidad de La Laguna, que lleva por nombre Castilla y el Mar en la Baja Edad Media. Para este trabajo serían interesantes las aportaciones de proyecto nacional denominado El mundo social de las gentes de mar en Andalucia durante la Baja Edad Media. Véase "Europa y el mar: las nuevas fronteras", pp. 9-30; O'Callaghan, The Gibraltar Crusade. Castile and the Battle for the Strait.; García De Castro, La marina de guerra de Castilla en la Edad Media (1248-1474), finalmente Flores DíAz, Leones y castillos en la mar. Castilla y el dominio del mar en la Edad Media (1248-1476). Si tomamos en consideración las aportaciones existentes en el ámbito de la navegación comercial o la pesca, el número de aportaciones es aún mayor.
} 
En este trabajo vamos a intentar aportar una mínima gota de agua de mar en este vasto océano que son los estudios históricos actuales. Pero no nos centraremos en aquellas personas que tuvieron en sus manos las posibilidades de decisión, estudio también necesario y en los que las fuentes cronísticas suelen centran su atención. No en los nombres propios que puedan aparecer en los pocos documentos oficiales conservados. Tengo en mente a miles de personas anónimas que con su labor día a día, con sus vidas y también con sus muertes, hicieron posible la historia marítima en general, y naval en particular, de Castilla ¡Cuánto sufrimiento! ¡Cuántos hombres lejos de sus hogares! ¡Qué dura la labor de la navegación! Y si esta era dura ¡cómo no sería la navegación en combate!

Pese al impulso historiográfico desde los años setenta del siglo pasado, entre otros por la famosa escuela de Anales, la pregunta que surge es ise ha hecho este tipo de aproximación antes? Creo que es legítima y es lo que, entiendo, hay que plantearse antes de iniciar cualquier estudio, el consabido estado de la cuestión. Pero lo cierto es que, ya lo veremos, este tipo de acercamiento, sorprendentemente y desde mi modesto entender, está en sus primeros pasos con casi todo por hacer'.

Aún con la interesante aportación de todos estos trabajos, ¿es posible imaginarnos siquiera mínimamente a una tripulación, concentrada en el pequeño mundo que supone una embarcación? ¿Sabían nadar? ¿Qué enseres tenían consigo? ¿Temían la navegación?

\footnotetext{
4 Por indicar posibles aproximaciones más relacionadas con la historia de las mentalidades que con el presente trabajo, NAVARro GonZÁlez, El mar en la literatura medieval castellana. Es un ensayo sobre temas marítimos en las fuentes literarias de las Castilla medieval; FurTado, Island of Castile: Artistic, Liteary and Legal Perception of the Sea in Castile-Leon 1248-1450. Descargado https://scholarsbank.uoregon.edu/xmlui/handle/1794/12098. Como el propio título nos introduce, el marco cronológico es desde mediados del siglo XIII a mediados del XV y se centra en la percepción que del mar se tenía en Castilla, empleando para ello fuentes iconográficas, literarias y legales; LeBrero Cocho, "Hidrofobia medieval: miedos y peligros vinculados al agua en la literatura castellana del XV", pp. 261-284. Emplea como fuente lo que denomina diarios de viajes, con cuatro textos que abarcan el siglo XV y con un epígrafe dedicado a los peligros del agua fuera del ámbito marino, crecidas, inundaciones, desbordamientos, etc.; Aníbarro Rodríguez, "Peligros marítimos de marineros del norte de la Corona de Castilla a finales de la Edad Media", 173-195, centrado cronológicamente también entre principios del siglo XV y principios del siglo XVI. Ofrece igualmente referencias de estudios sobre navegación comercial, pesca, la actividad corsaria, etc. Es interesante la parte dedicada a la situación en la que quedaban las familias, especialmente las mujeres, con la partida del hombre para navegar. En ámbito español, principalmente de la Corona de Aragón, pero sobre todo en el ámbito mediterráneo y en la Baja Edad Media, BADía; Cifuentes y SALICRÚ, (eds.) La vida marítima a la Mediterrania medieval. Fonts històriques i literaries. Es la publicación de los contenidos del II seminario internacional del Museo marítimo de Barcelona del año 2016 y de contenido, por su propia naturaleza, muy variado. Un aspecto muy concreto, el sanitario, se podría ver, para un marco general, en la obra de Pezzi, "Naval medicine in antiquity and the Middle Ages" pp. 420-435. Lamentablemente este trabajo, por diversas circunstancias, no ha podido ser consultado. No obstante, tenemos una excelente aproximación para ámbito hispánico con el artículo de CifuENTES, "La medicina en las galeras de la Corona de Aragón a finales de la Edad Media: la caja del barbero y sus libros", pp. 2-15. Facilita además bibliografía adicional. De forma genérica, GraCiAs RivAs, "La asistencia sanitaria a bordo de los buques. De la antigüedad clásica al siglo XVI", pp. 157-178. Aunque en este último la Edad Media se despacha entre las páginas 160 y 162, con datos de la Corona de Aragón que el autor hace extensibles a Castilla.
} 
¿El combate? ¿Ambas cosas por igual? ¿Cuáles eran sus motivaciones para embarcar? Yo creo que estas preguntas no se han hecho antes y no porque no pudieran tener interés. A muchas de las cuestiones anteriores podríamos, a lo mejor, acercarnos desde una vía comparativa. Pero podemos y debemos preguntarnos ison estos variados aspectos iguales y universales? A otras cuestiones nos podemos acercar mediante la escasa información textual disponible. La mayoría de las preguntas quedarán sin respuesta.

Respecto a la posible primera vía de aproximación, la comparativa, desde luego no sería una historia comparativa al uso 5 . No sería comparar (dudo si emplear mejor el término extrapolar), por ejemplo, entre diversos protagonistas de distintos marcos geográficos en un mismo momento cronológico, sino de algo un tanto más difuso. Se trataría mas bien de ver si ciertos sentimientos (miedo, temor, incertidumbre, etc...) pueden ser extrapolados de nuestro marco cronológico de estudio al, por ejemplo, el actual. Si pudiéramos considerar ciertos sentimientos más o menos comunes y perdurables a lo largo del tiempo (¿lo son de verdad?), vemos cómo en las fuentes documentales se muestran aquí y allá pequeños retales de información, indicios, ecos lejanos que nos pueden facilitar pistas que ayudan a encontrar respuestas a algunas de las cuestiones planteadas. Aún así, estas respuestas no plantean sino más preguntas y dudas.

De las fuentes empleadas, éstas serán principalmente de dos tipos: legales y cronísticas. Respecto a las primeras, emplearemos el texto conocido como Fuero o Leyes de Layrón, y en menor medida el de Las Partidas alfonsíes, de los que hablaremos un poco más adelante y que de hecho son las fundamentales para el siguiente punto. Una fuente jurídica anterior, de época visigoda, es el famoso Liber Iudiciorum, que tiene dos Libros, el V De transactionibus y el XI, De egrotis et mortuis adque transmarinis con algunos contenidos relacionados con el comercio marítimo. En total, entre los dos Libros, cinco capítulos, destacando los cuatro del Título III, De transmarinis negotiatoribus, del mencionado Libro XI. Pero no nos vamos a meter por estos vericuetos en este trabajo, mas allá de la mención a su existencia. También se hará referencia puntual a información existente en otras fuentes legales, como fueros o reglamentos, pero de forma muy marginal. Sobre las fuentes cronísticas, en mi opinión, como creo que se verá, son las que en numerosas ocasiones facilitan información, no sabemos hasta qué punto de forma totalmente consciente respecto a las implicaciones de la misma, de acercamiento a lo que, en un momento determinado, pudieran sentir los integrantes de una embarcación.

Pero antes creo que es bueno efectuar algunas observaciones y/o matizaciones previas, incluidas las terminológicas. Para empezar, no es lo mismo marítimo, relacionado con el mar, que naval, relacionado con las naves y por lo tanto con la navegación. Pero aquí el significado será un tanto diferente. Lo marítimo será lo relacionado con el ámbito civil/

Partiendo de la base que toda aproximación por comparación ha de hacerse con cuidado, sobre el método comparativo en Historia es interesante, Wickman y Salvador, "Comprender lo cotidiano: antropología social e historia social”, pp. 115-128. Una aplicación práctica es la obra del propio WickMAN, Framing the early Middle Ages. Europe and the Mediterranean 400-800. Y sobre la aplicación de dicho método sociológico, y también sus precauciones, el análisis de la obra anterior en GRACA, "Reflexiones metodológicas sobre el estudio comparativo de Chris Wickman", pp. 265-297. 
pacífico mientras que lo naval será lo relacionado con el ámbito bélico/guerrero en la $\operatorname{mar}^{6}$. La segunda cuestión es la del ámbito político y geográfico. No existió una Corona de Castilla como tal entidad política, con su aparato legal, organización administrativa, etc. Nuestra mención a una Corona de Castilla es estrictamente geográfica y temporal. Comprende a aquellos territorios que, en un momento u otro de la Edad Media, formaron parte de la órbita política directa de los reyes de Castilla en la Península Ibérica. Quedan excluidos por tanto el reino de Portugal, la Corona de Aragón, el reino de Navarra y el reino de Granada. Un tercer aspecto es que, aunque usamos para el personal embarcado el gentilicio de "castellanos", lógicamente la procedencia geográfica de aquellos marinos que rindieron sus servicios a la causa de la monarquía castellana, podía tener orígenes variados. Nos referimos a marinos que realizaron sus servicios a la monarquía castellana atendiendo a los requerimientos de ésta conforme a las variadas formas de reclutamiento existentes a lo largo de este periodo, muchas veces de forma solapada, sin excluir unas de otras ${ }^{7}$. En el uso de embarcaciones mercantiles el criterio sería el mismo.

Para este análisis, en el siguiente punto intentaremos ver cuáles eran las condiciones de vida de los tripulantes de las embarcaciones. Después veremos si podemos acercarnos a lo que pudieran sentir los mismos en las acciones para el combate. Tras esto, pasaremos a la perspectiva de la influencia de las condiciones meteorológicas. Lo último será una observación sobre una situación que podemos definir como de realidad incómoda, cuanto no de penuria y miseria, al aproximarnos a auténticas situaciones de sufrimiento por el hambre. Finalizaremos con las oportunas conclusiones que se puedan obtener, así como la preceptiva nómina de las fuentes y bibliografía empleadas para esta aproximación.

\section{Las condiciones de vida}

Creo que una característica común en los trabajos mencionados en el punto anterior, incluidos el de quién suscribe, es que están faltos en intentar mostrar la perspectiva, aunque sea muy aproximada, de las condiciones de vida de quienes estaban embarcados. Intentemos remediar, aunque sea mínimamente, esta situación y aproximémonos a éstas.

\subsection{La vida embarcado}

Los testimonios directos contemporáneos que nos indiquen cómo eran las condiciones de vida en una embarcación son escasos, por no decir inexistentes, pero es factible hacer una aproximación por vías indirectas.

Una de estas vías nos la facilita el análisis de los textos legales que hacen referencia a las actividades mercantiles por vía marítima. Si dejamos a un lado el escaso contenido

\footnotetext{
6 Aclaraciones adicionales de terminología en varios trabajos de Flores Díaz, en especial Leones y castillos en la mar, pp. 22-25.

7 Sobre las formas de reclutamiento de embarcaciones y hombres, véase la obra anterior, pp. 558-569 para las embarcaciones y pp. 572-575 para los hombres.
} 
que sobre el tema existe en algunos fueros locales de localidades costeras, la información más significativa para Castilla proviene del texto legal conocido como Leyes o Fuero de Layrón. Este es la versión del texto europeo conocido como Rôles D'Oléron o, españolizado, Roles de Olerón ${ }^{8}$. Igualmente puede contener información el código legal de Las Partidas alfonsíes, pero ésta será escasa en lo referido a las condiciones de vida del personal embarcado, como veremos.

Respecto a los Roles de Olerón, la redacción de este texto tiene su origen en el siglo XIII y se difunde por la costa atlántica de Europa así como por el Báltico ${ }^{9}$. El conocimiento de la versión primitiva del mismo en Castilla se haría de forma temprana como consecuencia tanto de la proximidad geográfica como de la intensidad de los intercambios comerciales por vía marítima ${ }^{10}$.

En las versiones castellanas conocidas, uno de los dos grupos de preceptos más abundantes, con cuatro artículos, son los relacionados con la disciplina interna de las embarcaciones, necesaria para hombres que van a pasar mucho tiempo juntos en un espacio que debía ser muy limitado ${ }^{11}$. Un ejemplo de este tipo es el siguiente:

«Aviene que el maestre e sus marineros estando en la tabla a comer rreqreçensce departimientos e palabras entre los marineros, el maestre es tenido a poner entre ellos paz e sosiego. E sy algund marinero desmiente a otro estando en la tabla debe pagar quatro dineros parasines. E si el maestro desmiente a algund marinero debe pagar ocho dineros parasines, E si algund marinero desmiente al maestre debe pagar ocho dineros parasines. E si contienda ha entre el maestre e algund marino, el marino lo debe atender la primera punnada o palmada, e si el maestre lo quiere dar mass el marino se puede bien defender, e si el marino fyere primero debe perder çiento suelds de la dicha moneda o el punno qual quisiere el marino. Este es el juycio en este caso» ${ }^{12}$

Otro grupo significativo de preceptos, entre tres y cuatro artículos según el manuscrito, sí que tiene mayor relación con las condiciones de vida abordo, tales como suministros, alojamiento, manutención, cuidados en caso de enfermedad, fallecimiento de un tripulante... ${ }^{13}$. Por ejemplo:

\footnotetext{
8 Sobre los Roles de Olerón, véase la obra de Serna Vallejo, El cotumier marítimo del Atlántico y del Báltico de época Medieval y Moderna. Santander. De las Leyes de Layrón, Flores Díaz, Hombres, barcos e intercambios. El Derecho marítimo-mercantil del siglo XIII en Castilla y Aragón. Estas dos obras son nuestra guía para el desarrollo de este punto. Para el uso efectivo de este texto como fuente jurisdiccional, véase SERNa VALLeJo, pp. 169-171.

9 Serna Vallejo, El cotumier marítimo, p. 19.

10 Ibidem, p. 71.

11 Flores Díaz, Hombres, barcos e intercambios, p. 109.

12 Leyes de Layrón, Biblioteca Nacional de Madrid, Sección de Manuscritos, Mss. 716, folios 91-94. Precepto 12.

13 Flores Díaz, Hombres, barcos e intercambios, p. 110.
} 
«Dolençias o feridas avienen a uno o dos o mas façiendo el servicio de la nao et non pueden estar en la nao tanto esta flaco. El maestre lo debe poner [roto] en una casa. $\mathrm{E}$ le debe dar graseta ardente o cirudelas et un moço de la nao que lo sirva o alogar una mujer que lo sirva. El maestre lo debe proveer de tal vianda commo dare a otro en la nao, esto es a saber que le debe dar tanto commo dependería en la nao sy sano fuere e non mas. E sy el doliente quiere aver viandas mas delicadas e de mayor costo, el maestre non es tenudo de que las dar e la nao non debe demorar por el, antes deve yr e seguir su viaje. E si el dicho marinero guaresciere debe [roto] su soldada toda. E si el muriere develo aver su mujer o sus legítimos herederos. Este es el juyzio en este caso» ${ }^{14}$

De forma general el texto también tiene preceptos relacionados con la manutención del personal embarcado. Por ejemplo:

«Los marineros de la costa de Bretanna non deben aver mas de una cosina al día por rrason que ellos han bevraje yendo e viniendo. E los marinos de Lormandia deben aver dos cosinas al día por rrason que ql maestre no les da synno agua quando ellos van a buscar fretes. Pero quando ellos llegaren a tierra do naçe el vino, el maestre les debe dar bevraje de vino temprado en buena manera

E este es el juyzio en este caso» ${ }^{15}$

Pero, además, sobre el agua potable: «...E si quisieren meter un tonel de agua ellos lo pueden bien meter cada uno su parte que es el quarto de tonel a cada marinero... $\rangle^{16}$

Y otro ejemplo:

«Una nao acaesçe en Bordel o en otro lugar cualquier. De la cosina que ha la nao los marineros pueden levar fuera una pieça tal commo deben aver los marineros en la nao. E del pan que avra en la nao ellos deben aver tanto commo podrán comer. $\mathrm{E}$ fura de la nao non deben aver punto de bebraje» ${ }^{17}$.

\footnotetext{
14 Leyes de Layrón, Biblioteca Nacional de Madrid, Sección de Manuscritos, Mss. 716, folios 91-94. Precepto 7.

15 Ibidem. Precepto 17.

16 Ibidem. En el precepto 18

17 Ibidem. En el precepto 21.
} 
Es decir, si salen de la embarcación pueden tener la misma comida facilitada por la embarcación que si están dentro, pero no la misma bebida, al menos no el bebraje.

Estos preceptos, tantos los vistos como otros similares, denotan en definitiva la obligatoriedad, al menos legal, de unas ciertas condiciones de bienestar para las personas que van a desarrollar un trabajo que podríamos considerar más duro que otro y con unos peligros que le son propios por el entorno físico en el que se desarrolla.

En Las Partidas, encontramos una profusión normativa, especialmente en la Partida V, título noveno intitulado De los navios y de los pecios de ellos, con catorce leyes. En alguna de estas se indica cuáles son las épocas más favorables para la navegación y cuáles las menos, con el objetivo de, entre otras cosas, minimizar el riesgo de pérdida de vidas humanas ${ }^{18}$. En la ley primera de este título se expresa, entre otras muchas cosas:

«Otrosí están obligados [loa maestres y patronos] a abastecer a los navíos de armas y bizcocho y agua dulce y de las otras cosas que hubiere menester para su vianda ellos y sus marineros; y deben apercibir a los mercaderes y a los otros hombres que tuvieren que llevar en los navíos que hagan eso mismo, de manera que lleven agua y vianda la que les fuera menester, y aún armas aquellos que las pudieran traer, por defenderse de los corsarios y de otros enemigos, si menester fuere».

Las embarcaciones han de ir adecuadamente pertrechadas tanto para la alimentación del personal embarcado como para la adecuada defensa. Lo referido a la alimentación no deja de ser una cuestión recurrente dentro de la legislación que podemos encontrar en el ámbito mediterráneo, por ejemplo, en el Libro del Consulado del Mar, que de manera detallada, precisa la obligación de dar carne tres veces por semana, domingo, martes y jueves, menestra el resto de los días y "companage" todos los días por la tarde, así como vino seis veces al día, tres por la mañana y tres por la tarde ${ }^{19}$. Esto no hace más que podamos preguntarnos si la motivación para tanta insistencia no sería precisamente la falta generalizada de una alimentación adecuada. Pero esto, como veremos, no es así. Las leyes décima y decimoprimera nos llevan a la cuestión de los peligros derivados por la codicia, bien sea desde dentro o desde fuera de las embarcaciones. Así, la décima trata sobre la pena que merecen los marineros que hacen naufragar los navíos en los que están embarcados, para de esta forma obtener las mercancías de los mismos. La siguiente norma trata sobre los pescadores que hacen señales de fuego desde la costa para hacer naufragar a los navíos con las mismas intenciones.

\footnotetext{
18 Véase Arias Bonet, "El derecho marítimo en las Partidas", pp. 91-108. Una nómina de preceptos de las Partidas sobre el mar en Flores Díaz, El mar, fuente de Derecho en la España medieval. Expansión comercial y desarrollo legal, siglos XI-XIII. P. 88, nota 60.

19 Véase Aníbarro Rodríguez, "Peligros marítimos de marineros del norte de la Corona de Castilla a finales de la Edad Media", p. 189. El diccionario de la Real Academia de la Lengua define "companaje" como "Comida fiambre que se toma con pan, y a veces se reduce a queso o cebolla".
} 
Como se puede comprobar, respecto a las condiciones de vida del personal embarcado, estas fuentes muestran una preocupación de que exista un correcto aporte de comida y agua potable, tanto si están embarcados como no, por cuestiones de salud personal, tienen que residir fuera de la embarcación. A este respecto siempre ha sido una necesidad perentoria el contar con el adecuado suministro de agua potable. Así, los puntos de posible aguada en la costa o cerca de ella, pueden condicionar la navegación ${ }^{20}$.

Lamentablemente no he podido localizar testimonios similares referidos al personal embarcado para el combate. Sí que existen algunas pistas sueltas en otro tipo de documentación. Así, para los preparativos de la flota que se estaba organizando contra Aragón en 1429-1430, el rey ordenó el envío de instrucciones, entre otras muchas personas respecto a labores varias, a Alfonso Guillén de Caso, tenedor de los hornos del bizcocho de Sevilla ${ }^{21}$.

Como idea, pienso que las condiciones no debían ser muy diferentes, según parece entenderse en las últimas líneas del texto alfonsí que hemos visto anteriormente, pero es sólo una teoría.

No existe mucha información sobre los cuidados sanitarios. Hemos visto en páginas anteriores como para el caso de actividades mercantiles se procura cierto bienestar para aquellos que caen enfermos, al menos eso viene reflejado en las Leyes de Layrón. Pero no hay indicación de la existencia de personal sanitario embarcado. Hay pistas, muy someras, en fuentes sobre cuestiones bélicas, aunque sólo sea porque en la nómina del personal embarcado y sus funciones, aparezcan individuos con la calificación de "cirujano", como por ejemplo en $1380^{22}$. Aunque probablemente fuera común su embarque en el siglo XV, este se debía hacer no sin problemas. Esto se puede apreciar con la negativa del concejo de Jerez a aportar cirujanos para la flota que se estaba armando para combatir contra Aragón en 1429-143023.

\footnotetext{
20 Véase PRYOR, "«Water, water, everywhere, nor any drop to drink». Water supplies for the fleets of the First Crusade" En Ballard, Kedar, y Rilex-Smith, (Eds.) Dei Gesta per Francos: Etudes sur les croisades dediées a Jean Richard-Crusades Studies in Honour of Jearn Richard, pp. 21-28.

21 García IsaAc e IdÁÑez Vicente, "La flota castellana durante la guerra contra la Corona de Aragón de 1429-30: armamento de buques, tripulaciones, ordenanzas navales y campaña bélica", pp. 75-100. Para esta cuestión, p. 79.

22 García Isaac e IdéÑez Vicente, "Una investigación naval en Santander a finales del siglo XV: La pesquisa de Juan Rodríguez de Salamanca contra Gonzalo Pérez de Herrera”, p. 84.

23 García IsAaC e IdÁÑEZ Vicente, "La flota castellana durante la guerra contra la Corona de Aragón de 1429-30", p. 83.
} 


\subsection{La guerra en la mar}

No sé si resulta obvio plasmarlo aquí, pero la guerra no constituía el único marco de violencia relacionada con el combate en la mar. Las actividades de corsarios y piratas eran, en muchas ocasiones, un peligro cierto.

Salvo los documentos legales, relacionados con posibles reclamaciones económicas y de recuperación de mercancías y no con las sensaciones o sentimientos de los protagonistas activos o pasivos, contamos con escasa documentación al respecto. Lo cierto es que las descripciones más vívidas nos vienen de mano de la cronística, más centrada en los conflictos que podemos denominar como formales, las guerras. Sin embargo, estas tampoco ofrecen mucha información sobre posibles sentimientos grupales o individuales a la hora de afrontar el combate ${ }^{24}$.

Ya lo sabía en la segunda mitad del siglo XIII Alfonso X, cuando, volviendo a Las Partidas, indicaba en la Segunda, título XXIIII, Ley 1, que: «La guerra de la mar es como cosa desesperada y de mayor peligro que la de la tierra por las grandes desventuras que pueden en ella acaecer $\rangle^{25}$.

Se tiene constancia de cómo la guerra, ya de por sí una actividad peligrosa para el que la ejerce, y no sólo, se torna más arriesgada si se hace en el ámbito de la navegación ${ }^{26}$. Si intentamos aproximarnos a eventos concretos, no sabemos si, a mediados del siglo XIII, sintieron alegría los marinos del Cantábrico cuando rompieron con sus naves el puente de barcas sobre el Guadalquivir, en la acción naval central de la campaña de la toma de Sevilla. Es de suponer que sí, de la misma forma que también es fácil suponer que previamente pudieran tener sentimientos mezcla de temor e incertidumbre ante empresa tan arriesgada.

Casi cien años después, ¿acaso no debieron sentir miedo los tripulantes de la embarcación del almirante de Castilla Alfonso Jofre Tenorio cuando en febrero de 1340 la flota castellana sufrió una grave derrota? El texto cronístico se centra en la figura del almirante, pero cuando se lee, no deja de impactar lo que probablemente debió haber

\footnotetext{
24 Interesantes estudios sobre la psicología del combate son los de Grossman, On killing. The Psychological cost of learning to kill in war and society y Grossman, y Christensen, On Combat. The Psychologic and Physiology of death conflict in war and peace. Hay traducciones al español Matar: el coste psicológico de aprender a matar en la guerra y en la sociedad y Sobre el Combate. La psicología y fisiología del conflicto letal en la guerra y en la paz. Aunque enfocado el primero principalmente en las sociedades occidentales industriales surgidas a partir de principios del siglo XIX, muchos de los aspectos, creo, pueden extrapolarse, con las debidas precauciones, a cualquier época y sociedad. El segundo es un estudio detallado a partir de experiencias personales de combate de principios del siglo XXI.

25 Martínez Martínez, Acerca de la guerra y de la paz, los ejércitos, las estrategias y las armas según el libro de las Siete Partidas, p. 104.

26 En la obra On Killing, en el capítulo dedicado al reino del miedo (The Reign de Fear), existe un apartado específico, Fear and Sailors in Naval Combat, pp. 57-58, en el que se indica que, por miles de años, hasta el siglo XX, las batallas navales implicaban, como en tierra, la necesidad de un combate de muy corto alcance, con armamento como el arco, la ballesta o los cañones, existiendo muchos ejemplos de bajas psiquiátricas como resultado de este tipo de combate, según el autor.
} 
sucedido al resto de los tripulantes de la embarcación en la que estaban combatiendo y sin posibilidad de huir:

«E los moros de las galeas que peleauan con ellos entraron tres vezes en la galea del almirante [...] E desque vio que no tenia gentes con que la defendiesse, nin le acorrie ninguno, abraço el estandarte con el vn braço, e con el otro peleaua e esforçaua los suyos quanto podia e mandauales que estoviessen alli con el. E pelearon tanto hasta que los mataron todos delante; e el abraçado con el estandarte peleo con la espada que tenia en la mano, fasta quel cortaron la vna pierna e ouo de caer; e lançaron de ençima dela nao vna barra de hierro e diole vn golpe en la cabeza de que murio. [...]

...anssy que de toda la flota que el rrey de Castilla tenia non escaparon mas de çinco galeas» ${ }^{27}$.

En otro caso de unos años antes, en concreto de mayo de 1337 y del que tenemos noticia por el canciller Pedro López de Ayala esta vez en un enfrentamiento contra portugueses en aguas cercanas a Lisboa, es la impactante descripción tras la batalla «...e fueron tomadas ocho galeas de las de los portogaleses e anegadas seis; e murieron muchas gentes de amas parte, en manera que la mar era tinta de sangre muy gran parte della en aquel lugar» ${ }^{28}$. No deja de producir pesar y estremecimiento esta última frase. ¿Qué sentían los combatientes en los momentos previos a la batalla? Momentos como los que nos relata, por ejemplo, Jean Froissart en el siglo XIV justo antes de la batalla de La Rochela:

«El día de la vigilia de San Juan del año de mil trescientos y setenta y dos sucedió que el conde de Pemboke debía arribar con sus tropas al puesto de La Rochela, pero se encontraron delante a los españoles que les disputaron la orilla y mucho se alegraron de su llegada» ${ }^{29}$

¿Era ansia de violencia gratuita, de acabar con la acción contraria del enemigo, venganza, obligación o un medio de obtención de riqueza rápida lo que movió a los hombres en los diversos ataques contra las costas del sur de Inglaterra en 1377, 1380 y 1405-1406? En los dos primeros casos por parte de sendas flotas bajo mando de Sánchez Tovar y en la tercera ocasión por parte de Pero Niño, en todos los casos siempre por orden del monarca castellano. Probablemente la contestación sea una combinación de todo lo indicado en la pregunta. La cuestión sería saber el porcentaje.

\footnotetext{
Gran Crónica de Alfonso XI, p. 317.

28 López De Ayala, Crónica de los Reyes de Castilla, p. 186.

29 Froissart, Crónicas, p. 277.
} 
Hay además algunos ejemplos, pocos y tardíos, de muestras públicas de sentimientos. Por ejemplo, ¿era inducido o espontáneo el "ardor guerrero" (por así llamarlo) de los marineros vascos que en 1456 ayudaron a la toma de la localidad de Fuengirola, según nos presentan numerosas crónicas de la época?

«Y en este dia como la gente del real pasasse junto con la Fuengirola e les pareçiere que la fortaleza se podía tomar, començaron de la combatir, e como los moros todos socorrieron a la parte del combate e las espaldas de la fortaleza quedasen syn gente alguna, la gente de un ballener que era de uno que se llamava Oían Viral, salio en tierra e con el mastil del ballener escalaron la fortaleza, e subieron en ella catorze o quinze vizcaynos, dando muy grandes bozes, ¡Castilla, Castilla, por el rey don Enrique! $\rangle^{30}$

También está descrita esta acción, de forma más somera, en el Memorial de diversas hazañas $^{31} \mathrm{y}$ en Galíndez de Carvajal ${ }^{32}$.

Es muy difícil, por no decir pretencioso, intentar meterse en la mente de otra persona para intentar llegar a su pensamiento, así que nos tendremos que conformar en este punto con más suposiciones y preguntas sin contestar que con certezas, aunque los sentimientos de temor o alegría indudablemente estaban ahí con cada acción, no sólo de navegación, sino principalmente de combate y, saliendo vivo de ambas, no debía ser lo mismo estar entre los que puntualmente pudieran salir victorioso que entre los que no.

\subsection{La climatología, el factor impredecible}

Pero, ya sea en guerra o en paz, el peligro durante la navegación podía venir en cualquier momento. A principios del siglo XIV, el intento fallido de toma de Algeciras en 1309 se vio afectado, entre otras cosas, «Porque non podían aver viandas por mar nin por tierra é por la grand tormenta que facia en la mar é las grandes aguas $»^{33}$.

Pero la climatología no siempre se reseñaba desde una perspectiva negativa. A veces se pedía y obtenía de la divinidad que esta fuera beneficiosa. Unos años después de lo sucedido en el párrafo anterior, en el desarrollo de la campaña de Gibraltar: «E fue toda la merced de Dios en dar buen tiempo qual auian menester $\rangle^{34}$.

Como nos indica otra vez el canciller Ayala, en una ocasión, en la previa a la batalla de Tarifa-El Salado, más avanzado el siglo XIV, una tormenta dispersó a las embarcaciones

\footnotetext{
Sobre la campaña, Crónica Anónima de Enrique IV, vol. II, p. 54

Memorial de Diversas Hazañas: Crónica de Enrique IV, p. 33.

Galíndez De Carvajal, Crónica de Enrique IV, cap. 21, p. 116.

Crónica de Fernando IV, cap. XVII, p. 164.

Gran Crónica de Alfonso XI, vol. 2, p. 55.
} 
de la flota castellana desde el Estrecho hasta Cartagena y Valencia, y esto a las que no perecieron en la misma:

«E en aquella noche, estando el prior en la guarda de la mar [...] vino tan grand tormenta en la mar de guisa que se perdieron las nueve galeas, que fueron quebradas a la costa de la mar [...] e corrieron con aquella tormenta las vnas fasta Cartagena e las otras fasta Valencia....» ${ }^{35}$

No toda influencia meteorológica es necesariamente productora de consecuencias nefastas. Así, la primera presencia castellana en las Canarias por parte de Martín Ruíz de Avendaño se debe a que arribó a las costas de Lanzarote, al parecer, empujado por una tormenta $^{36}$. Y también, más tarde, a principios del siglo XV, en el marco del proceso de asentamiento castellano, el hecho de que la expedición de Jean de Bethencourt tardase únicamente cinco días en hacer la travesía desde la Península hasta Lanzarote ${ }^{37}$.

También de principios del siglo XV tenemos la información que nos proporciona la crónica que narra los sucesos de Pero Niño, conde de Buelna. En el inicio de sus actividades marítimas, en el Mediterráneo, el autor del texto destaca la sensación de peligro que existía ante el fenómeno de la niebla y el temor sobrenatural que suscitaba, pese a ser un fenómeno conocido:

«Conteçio allí una maravilla a los que tal non avían visto. Viniendo las galeas remando, costeando la tierra, la mar calma, podría aver fasta Málaga quando dos millas, e mediando el mes de mayo, el cielo muy claro, el sol a sudeste, levantóse a deshora una niebla muy oscura, que venía de contra la çivdad, e vino sobre las galeas, en manera que los de la una galea non veýan a los de la otra, aunque estaban bien çerca ${ }^{38}$.

Más adelante es increíble, con tintes homéricos, el periplo de regreso a Castilla de la pequeña flota de Pero Niño desde el canal de La Mancha. Este regreso se enmarca en el final de sus campañas en la zona, después de recibir órdenes del monarca castellano al respecto cuando se encontraba en el puerto de Brest. Desde este puerto terminaron inicialmente en Sain-Malo, más hacia el Este. Desde allí aproaron al Oeste, llegando a la isla de Batz. Debido a las condiciones meteorológicas y de la mar, en la siguiente singladura se vieron forzados nuevamente a ir al Este, hasta Monte San Miguel, más al Este aún que Saint-Malo. Desde Monte San Miguel aproaron al Oeste y después al

\footnotetext{
López de Ayala, Crónica de los Reyes de Castilla, p. 369.

6 CABrera Pérez, "El Redescubrimiento", p. 104.

3 Salle, Le Canarien, vol. III, p. 20.

38 Díez De Games, El Victorial. Crónica de Don Pero Niño, conde de Buelna. Tomado de Aníbarro Rodríguez, "Peligros marítimos de marineros del norte de la Corona de Castilla a finales de la Edad Media", p. 176.
} 
Suroeste, llegando hasta La Rochela. Desde allí arrumbaron ya a Castilla directamente, arribando primero al puerto de Pasajes y después al destino definitivo, el puerto de Santander. Hay que indicar que las fechas no eran las más propicias, siendo ya octubre cuando iniciaron su salida de Brest ${ }^{39}$.

Otro ejemplo, también más relacionado con una cuestión estacional que la propiamente meteorológica, y ya a principios del siglo XV, fue que en 1410 la flota reunida para la campaña contra Granada se disolvió en el otoño con la llegada del mal tiempo ${ }^{40}$.

No cabe duda, revisando este punto, que las inclemencias meteorológicas condicionaban las operaciones navales y, además, suponían una posibilidad cierta de peligro, incluso para la propia vida ${ }^{41}$. Pero si hay algo que destaca, es el silencio de las fuentes empleadas a la hora de saber con qué ánimo lo afrontaban o qué sentían las personas sometidas a semejantes pruebas. A lo mejor es tan evidente que no les merecía la pena hacer comentario alguno. A lo mejor las vidas de personas, anónimas a nuestros ojos, no eran socialmente lo suficientemente importantes para reseñar estas circunstancias. A lo mejor...Lo que a mi entender sí que quedaría claro, sería la mezcla de sensaciones de alivio, fortuna, agradecimiento o salir con vida de semejante situación, así como de tristeza y pesar por los compañeros y posibles amigos que fueran menos afortunados.

\subsection{La realidad incómoda}

En las páginas anteriores, al hablar de las condiciones de vida, hemos mencionado que los textos legales muestran interés por lo relacionado con la alimentación y que el personal embarcado pudiera contar con unos mínimos aceptables para la época en función del duro trabajo que tenían que realizar. Indicábamos también si a lo mejor esto no era reflejo precisamente de la ausencia de condiciones alimenticias adecuadas. A tenor de lo que veremos, la respuesta es que no, que el personal embarcado para actividades, al menos comerciales, tenía una adecuada fuente de alimentación. $Y$ teniendo en cuenta esto, algunas situaciones que se dieron en embarcaciones al servicio de los intereses políticos de los monarcas no dejan de ser aterradoras.

¿Cuánta hambre, angustia y desesperación no debieron pasar los hombres que a finales del siglo XIII asediaban Algeciras por mar? Al menos, tal y como se desprende de la Crónica de Alfonso $X$. Este texto indica expresamente la falta de pagas y suministros, tanto de vestimenta como de alimentos, durante todo el invierno. Así, los que no estaban enfermos, tuvieron que dejar desamparadas las embarcaciones para, como coloquialmente se dice, buscarse la vida:

\footnotetext{
3 Díez De Games, El Victorial. Crónica de don Pero Niño, conde de Buelna, pp. 633-637 y 648-650. Está claro que se trata de una fuente de referencia con entidad propia para tratar este tipo de cuestiones.

40 García De Santamaría, Crónica de Juan II de Castilla, p. 404.

41 PRYOR, "Winds, waves and rocks: the routes and the perils along them", pp. 71-85.
} 
«...los de la flota avían estado en la guarda de la mar todo el invierno, e non les avían fecho sus pagas como devían, nin avian avido ningund refrescamiento de vestidos nin de viandas [...] cayeronseles los dientes e ovieron otras muchas dolencias porque oviesen a salir de la mar e desamparar las galeas [...] e todas las galeas e las naves desamparadas, que non avian en ellas gentes, sinon muy pocas en cada una, e estos dolientes e lacerados... $\rangle^{42}$

En 1339, en los preparativos de los combates contra los benimerines, se nos indica en una información contenida en la Gran Crónica de Alfonso XI: «E otrosy anbiaua paga e refrescamiento a los de la flota que estauan en la mar guardando el Estrecho ${ }^{43}$. En esta misma fuente, de principios de $1340 \mathrm{y}$ sobre el estado de la flota:

«...e dixole que don Alfonso Jufre Tenorio su almirante mayor estaua en la guarda de la mar con poca flota, y como auia ay estado todo el invierno y que tenia las galeas muy desbaratadas de gentes [...] e otrosi auian ay ocho galeas que estauan al puerto de Sancta Maria, por que non avian gentes que fuesen e ella...» ${ }^{44}$

Además, el personal embarcado que estaban en ella presentaba un estado deplorable debido a las graves carencias y falta de cuidados:

«...e por cierto las compañas de la flota estauan las mas flacas y dellas dolientes de los tiempos fuertes que auian pasado, a avn tales ay auian que se les cayerosn los dientes con los fríos e las grandes enfermedades que auian, como omes que atan grande tiempo auie que andauan sobre la mar o no auien salido a tierra para tomar refrescamiento segund lo fazen los omes que andan sobre $\operatorname{mar}\rangle^{45}$

Cincuenta años después de lo visto según lo narrado por la Crónica de Alfonso $X$ sobre la campaña de Algeciras, la situación para los tripulantes que permanecían mucho tiempo embarcados en campaña, no parece que mejorara. Y eso que la dotación de alimentos era una constante en la legislación mercantil civil como hemos podido ver en las páginas anteriores, de ahí, quizás, el interesante final del texto «...segund lo fazen los omes que andan sobre mar».

\footnotetext{
Crónica de Alfonso X, cap. LXXII, p. 55.

3 Gran Crónica de Alfonso XI, vol. 2, p. 263.

44 Ibidem, p. 308.

45 Ibidem, p. 315.
} 
La falta de dotación para las embarcaciones y la escasez de las mismas es una circunstancia que se volverá a repetir, por ejemplo, en 1370, cuando Enrique II mandó armar flota en Sevilla contra los portugueses, encontrándose con que había escasez de remeros, lo que dificultaba la navegabilidad de las embarcaciones ${ }^{46}$. Pasado el tiempo, al principio del reinado de Juan II, siendo su tío Fernando uno de los regentes del reino, este es informado en 1408 por el almirante Alfonso Enríquez de que sólo dispone de cinco galeras, pero, además, no se tenía para las mismas ni dotación humana ni material ${ }^{47}$.

¿Fue la necesidad económica y no poder abandonar sus quehaceres diarios? ¿El miedo a lo que pudiera deparar la guerra? ¿Una combinación de las dos cosas? lo que motivó que el concejo de Murcia no pudiera facilitar los remeros solicitados para las embarcaciones a poner bajo el servicio del rey. El intercambio epistolar entre Juan II y su tío Fernando, desde mayo de 1412 hasta enero de 1413 nos da pistas sobre la falta de remeros ${ }^{48}$. Cruce de misivas que se inició por las pesquisas mandadas efectuar por el soberano castellano ante la negativa de ciertas personas a acudir como galeotes a la flota que se estaba formando para combatir contra los granadinos.

También en la campaña prevista contra Aragón en 1429-1430 por parte de Juan II, la movilización de la flota se vio afectada por la escasez de galeotes y el retraso en la paga a los patrones de las naos ${ }^{49}$. Esta falta de galeotes hizo que, por ejemplo, se enrolara por la fuerza a labradores que se dirigían a desempeñar su labor a los campos de Jerez de la Frontera ${ }^{50}$.

Lo cierto es que tenemos retazos de información de los siglos XIII, XIV y XV que nos indican cómo las condiciones de vida del personal embarcado en operaciones bélicas, con la duda de la información del siglo XV, dejaban mucho que desear. Se puede aducir que los dos primeros ejemplos hacen referencia a condiciones extremas aisladas, de las que no hay otros ejemplos. No obstante, es legítimo pensar que se llegó a tal situación después de muchas penurias previas, sin que los encargados de remediarlo hicieran nada y que, seguramente, las condiciones de vida abordo serían de por sí muy duras.

\section{Conclusiones}

Hemos presentado en este trabajo unos pocos esbozos que permiten presentar ciertas consideraciones que trabajos futuros, y ahí se lanza un reto a quien quiera recogerlo, deberán completar, corroborar y/o modificar.

\footnotetext{
46 López de Ayala, Crónica de los Reyes de Castilla, pp. 444-446.

47 García de Santamaría, Crónica de Juan II de Castilla, p. 60.

48 Villaplana Gisbert, Colección de Documentos para la Historia del Reino de Murcia, vol. XV, pp. 353-354.

49 CAlderón Ortega, "La intervención de marinos cántabros y vascos en la campaña naval de 1430 y los intentos por extender la jurisdicción del Almirantazgo de Castilla a los puertos del norte peninsular", pp. 61-62. De la campaña, García IsaAC e IdÁÑez Vicente, "La flota castellana durante la guerra contra la Corona de Aragón de 1429-30".

50 García IsAaC e IdÁÑEZ Vicente, "La flota castellana durante la guerra contra la Corona de Aragón de 1429-30", p. 82.
} 
Podemos empezar indicando que las condiciones de vida no serían iguales para todo el mundo. Así, una primera diferenciación pudiera ser la que hay entre los marineros encargados del funcionamiento de la embarcación y el resto del personal embarcado, sea este personal civil en caso de actividades mercantiles o militar en el caso de actividades bélicas. No obstante, en las fuentes empleadas, no se ha podido establecer una diferenciación tan clara y tajante en las condiciones de vida y hablan al respecto de forma genérica, pese a que pienso que tales diferencias debían darse en una sociedad tan estamental como era sobre la que estamos enfocando nuestro objetivo. Parafraseando un concepto historiográfico que ha tenido cierto éxito, aunque para otro ámbito cronológico y actividad, pudiera ser que el mar fuese un "gran igualador", pero no tanto. No obstante, es igualmente legítimo el pensamiento contrario. Es decir, que el mar sí actuase como un completo igualador social. Realmente las fuentes empleadas no permiten ir hacia un lado u otro. Pero la idea de que, por ejemplo, Pedro López de Ayala tenía las mismas condiciones de vida a bordo de una embarcación que un marinero ordinario, resulta arriesgada.

Una segunda cuestión que destaca — pienso - es que para la navegación comercial, al menos en el plano teórico y desde el campo legal, se procuraban unas condiciones de vida mínimamente decentes y cierta seguridad e higiene en el trabajo. Los tripulantes realizaban una actividad arriesgada en un entorno de trabajo ya de por sí difícil, pero que garantizaba, al menos para alguno, unos beneficios que debían compensar con creces. Esta, por así llamarla, pero con mucha precaución, "protección social" se procuraba hacer extensible a las personas allegadas en caso de fallecimiento en el desarrollo de tales actividades.

En otro orden de cosas, llama la atención la escasez de referencias a los aspectos sanitarios, casi nulas para la navegación civil, al menos la comercial y muy escasas para la navegación bélica.

Una cuarta consideración es que se tenía conciencia de que la guerra por mar presentaba más riesgos para el personal embarcado que realizaba tal actividad como reflejaban Las Partidas de forma tan explícita. Estos peligros venían dados de forma cierta, tal y como reflejan las fuentes cronísticas, tanto por las consecuencias del combate en sí mismo (herida, mutilación, muerte), a las surgidas por la captura de las embarcaciones (cautividad, esclavitud) o específicamente el hundimiento de las embarcaciones (ahogamiento), esta última consecuencia más probable, no tanto entre la gente de mar de función principalmente náutico marinera, como entre la de armas, de función principalmente bélica. Si tenemos en cuenta la pesada dotación individual, tanto ofensiva como defensiva, del combatiente de la época, tanto de ballesteros como de hombres de $\operatorname{armas}^{51}$. Además, y esto es ya más hipótesis, si cabe, habría que contar con la presión

\footnotetext{
51 A este respecto hay que decir que, como curiosidad, en la actualidad, con los modernos elementos de protección balística ya sean metálicos o cerámicos, el casco, ya sea metálicos o de fibras compuestas y el armamento individual, aunque sea el moderno, con gran cantidad de elementos de polímeros de plástico, un soldado actual tiene poco que envidiar, en cuanto a peso, respecto a un guerrero medieval. Dejando a
} 
psicológica a la que, suponemos, debían enfrentarse quienes encaraban el catálogo de posibles peligros, tanto de la navegación como del combate.

Finalmente, estos riesgos no venían dados, en el caso de la guerra sólo por el hecho del combate en sí, que por otro lado era una posibilidad mínima, sino que venían aumentados por las inclemencias meteorológicas, que lógicamente también afectaba a la navegación comercial. En especial los fenómenos tormentosos que hacían difícil, sino imposible, el gobierno adecuado de la embarcación, que muchas veces tenía que dejarse al pairo. Pero también las brumas y nieblas, con el peligro cierto de abordaje entre embarcaciones o de aproximaciones no deseadas a la costa. Basta con la lectura de los fueros otorgados a las poblaciones costeras para darse cuenta de que la posibilidad de naufragio no era una cuestión aislada ${ }^{52}$. También existía el riesgo de una logística deficiente, especialmente en campañas bélicas, que impedía una adecuada nutrición del personal embarcado o, incluso, la reposición de vestimenta y las pagas. Los ejemplos descritos en las páginas anteriores lo muestran claramente.

Parece evidente que no todo el mundo actúa de igual forma ante circunstancias adversas, como también es cierto que una persona cualquiera, no actúa siempre por igual ante diversos avatares vitales. Pero también parece claro que ante una situación de peligro hay quien actúa activamente para tratar de pasarla, quien lo hace pasivamente y quien tiene en mente el "sálvese el que pueda". No sé si es un tópico. Se suele decir que en la adversidad es cuando se conoce a una persona. Y como hemos podido constatar, las posibilidades de adversidad en una embarcación castellana de la Edad Media eran ciertamente muchas.

Como gran conclusión y que muestra en cierta forma el hecho de no haber conseguido el objetivo de este trabajo al no poder cumplir con el planteamiento inicial del mismo, es decir, mostrar lo que sentían las personas embarcadas, pienso que ha quedado reflejado, la gran labor de investigación pendiente, como ya he avanzado, como por ejemplo mediante el empleo de otro tipo de fuentes que las aquí traídas. Un objetivo para el futuro, un reto que deberán plantearse los investigadores sobre la historia marítima, no solo naval, medieval de Castilla. En definitiva, la historia de unos hombres - si, aunque los textos no dicen casi nada, la inmensa mayoría, por no decir todos, eran hombres-, que en última instancia luchaban por sobrevivir, en un entorno a menudo muy hostil, junto con sus compañeros de embarcación, tanto en la paz como en la guerra.

\section{Fuentes y bibliografía}

Aníbarro Rodríguez, Javier, "Peligros marítimos de marineros del norte de la Corona de Castilla a finales de la Edad Media", Edad Media. Revista de Historia, 17 (2016) pp. 173-195.

un lado otro tipo de equipamiento, como elementos de hidratación, de comunicaciones, de visión nocturna, sanitarios, dotación de munición, dotación de alimentación, etc, etc, etc.

52 Véase Flores Díaz, El mar fuente de derecho en la España medieval, pp. 92-107. 
ARias Bonet, Juan Antonio, "El derecho marítimo en las Partidas", Revista de Derecho Mercantil, Madrid, 99 (1966) pp. 91-108.

Aznar Vallejo, Eduardo, "La guerra naval en Castilla en la Baja Edad Media", En la España Medieval, 32 (2009) pp. 167-192.

Aznar Vallejo, Eduardo y González Zalacain, Roberto J., "Europa y el mar: las nuevas fronteras", Vegueta. Anuario de la Facultad de Geografia e Historia, 18 (2018), pp. 9-30.

BAdíA, Lola; Cifuentes, Lluis y SALICRÚ, Roser (eds.), La vida marítima a la Mediterrania medieval. Fonts històriques i literaries. Barcelona, Museo Marítimo de Barcelona y Publicaciones de la Abadía de Montserrat, 2019.

Cabrera Pérez, José Carlos, El Redescubrimiento, en Morales Padrón, Francisco (dir.), Historia de Canarias, vol. I. Prehistoria-siglo XV. Prensa Ibérica, Valencia, 1991.

CAlderón Ortega, José Manuel, "La intervención de marinos cántabros y vascos en la campaña naval de 1430 y los intentos por extender la jurisdicción del Almirantazgo de Castilla a los puertos del norte peninsular", Itsas memoria. Revista de Estudios marítimos del País Vasco, 5 (2006), pp. 53-67.

Carriazo y Arroquía, Juan de Mata (ed.), Memorial de Diversas Hazañas: Crónica de Enrique IV. Madrid, Espasa-Calpe, 1941.

CASAdo Soto, José Luis, "Guerra naval, táctica, logística y estrategia”, en García Ballesteros, Luis (dir.), Historia de la Ciencia y la Técnica en la Corona de Castilla II, vol. 2, Edad Media, Valladolid, Junta de Castilla y León, 2002, pp. 567-588.

Cifuentes, Lluís, "La medicina en las galeras de la Corona de Aragón a finales de la Edad Media: la caja del barbero y sus libros", Medicina\&Historia, 4 (2000), pp. 2-15.

Crónica de Alfonso X. Biblioteca de Autores Españoles, vol. LXVI.

Crónica de Fernando IV. Biblioteca de Autores Españoles, vol. LXVI.

Díez De Games, Gutierre, El Victorial. Crónica de don Pero Niño, conde de Buelna. Beltrán Llavador, Rafael, estudio, edición crítica, anotación y glosario. Salamanca, Universidad de Salamanca, 1997.

DufourcQ, Ch.-E., La vie quotidienne dans les ports méditerranées au Moyen Age: Provence, Languedoc, Catalogne. Hachette, París, 1975.

Flores Díaz, Manuel, Hombres, barcos e intercambios. El Derecho marítimo-mercantil del siglo XIII en Castilla y Aragón. Madrid, Castellum, 1998.

Flores Díaz, Manuel, El mar, fuente de Derecho en la España medieval. Expansión comercial y desarrollo legal, siglos XI-XIII. Madrid, Asociación Cultural Castellum, 2000. Flores Díaz, Manuel, Leones y castillos en la mar. Castilla y el dominio del mar en la Edad Media (1248-1476), Madrid, Ministerio de Defensa, 2018.

Froissart, Jean, Crónicas. Cirlos Valenzuela, Victoria y Ruiz Domenec, José Enrique (eds.) Madrid, Siruela, 1988. 
Furtado, Michael Anthony, Island of Castile: Artistic, Liteary and Legal Perception of the Sea in Castile-Leon 1248-1450. Universidad de Oregón, 2011. Descargado de https:// scholarsbank.uoregon.edu/xmlui/handle/1794/12098

Galíndez De Carvajal, Diego, Crónica de Enrique IV. Torres Fontes, Juan (ed.), Estudio sobre la "Crónica de Enrique IV" del Dr. Galíndez de Carvajal. Murcia, Instituto Jerónimo Zurita, 1946.

García IsAac, José Marcos e IdÁÑEz Vicente, Carmen, "Una investigación naval en Santander a finales del siglo XV: La pesquisa de Juan Rodríguez de Salamanca contra Gonzalo Pérez de Herrera", Cuadernos Medievales, 24, junio (2018), pp. 78-99.

García IsAac, José Marcos e IdÁÑEZ Vicente, Carmen, "La flota castellana durante la guerra contra la Corona de Aragón de 1429-30: armamento de buques, tripulaciones, ordenanzas navales y campaña bélica", Historia. Instituciones. Documentos, 46 (2019), pp. 75-100.

García Sanz, Arcadio y Coll Juliana, Nuria, Galeres mercants catalanes dels segles XIV $i X V$. Barcelona, Fundación Noguera, 1994.

García de Santamaría, Alvar, Crónica de Juan II de Castilla. Carriazo y Arroquia, Juan de Mata (ed.) Madrid, Real Academia de la Historia, 1982.

García de CAStro, Francisco Javier, La marina de guerra de Castilla en la Edad Media (1248-1474). Valladolid, Universidad de Valladolid, 2014.

GraCA, Laura da, "Reflexiones metodológicas sobre el estudio comparativo de Chris Wickman”, Edad Media. Revista de Historia, 9 (2008) pp. 265-297.

Gran Crónica de Alfonso XI. Catalán Menéndez-Pidal, Diego (ed.), 2 vols. Madrid, Gredos, Seminario Menéndez Pidal de la Universidad Complutense, 1976, vol. 2.

Gracias Rivas, Manuel, "La asistencia sanitaria a bordo de los buques. De la antigüedad clásica al siglo XVI", Guerra, exploraciones y navegación: del mundo antiguo a la Edad Moderna. Curso de verano Universidad Internacional Menéndez Pelayo, Universidad de La Coruña, El Ferrol, 18 a 21 de julio de 1994, Víctor Alonso Troncoso (coord.), Universidad de La Coruña, La Coruña, 1995, pp. 157-178.

Grossman, Dave, On killing. The Psychological cost of learning to kill in war and society. Back Bay Books, Nueva York, 2009. Edición en español Matar: el coste pisicológico de aprender a matar en la guerra y en la sociedad. Melusina, Santa Cruz de Tenerife, 2014.

Grossman, Dave y Christensen, Loren W., On Combat. The Psychologic and Physiology of death conflict in war and peace. Human Factor Research Group, 2008. Edición en español, Sobre el combate. La psicología y fisiolgía del conflicto letal en la guerra y en la paz. Melusina, Santa Cruz de Tenerife, 2014.

Lebrero Cocho, Jorge, "Hidrofobia medieval: miedos y peligros vinculados al agua en la literatura castellana del XV” En Medievalismo, 25 (2015) pp. 261-284. 
Leyes de Layrón. Biblioteca Nacional de Madrid, Sección de Manuscritos, Mss. 716, folios 91-94.

López de Ayala, Pedro, Crónica de los Reyes de Castilla. MARTÍN, José Luis (ed.) Barcelona, Planeta, 1991.

Martínez Martínez, Julio Gerardo, Acerca de la guerra y de la paz, los ejércitos, las estrategias y las armas según el libro de las Siete Partidas. Cáceres, Universidad de Extremadura, 1984.

Navarro GonzÁlez, Alberto, El mar en la literatura medieval castellana. Universidad de La Laguna, La Laguna, 1962.

O'Callaghan, Joseph F., The Gibraltar Crusade. Castile and the Battle for the Strait. Philadelphia, University of Penssylvania Press, 2011.

Pezzi, G., "Naval medicine in antiquity and the Middle Ages", Annali di medicina navale, 60-4 (1955), pp. 420-435,

Pryor, J. H., "Winds, waves and rocks: the routes and the perils along them", K. Friend et alii (eds.), Maritime aspects of migrations, Coldgrave (1989), pp. 71-85.

PRYOR, J. H., “"Water, water, everywhere, nor any drop to drink». Water supplies for the fleets of the First Crusade", en Michel Ballard, Benjamin Z. Kedar y Jonathan Rilex-Smith (eds.), Dei Gesta per Francos: Etudes sur les croisades dediées a Jean Richard-Crusades Studies in Honour of Jearn Richard, Routledge (2001), pp. 21-28.

SAlle, Gadifer de La, Le Canarien, vol. III, p. 20, en Serra, Elías y Cionranescu, Alejandro (eds.), La Laguna, 1965.

SÁnchez PArra, María del Pilar, (ed.) Crónica Anónima de Enrique IV, vol. I. Estudio Crítico. Vol. II. Crónica castellana. Madrid, Ediciones de la Torre, 1991.

Serna Vallejo, Margarita, El cotumier marítimo del Atlántico y del Báltico de época Medieval y Moderna, Santander, Centro de Estudios Montañeses, 2004.

TAngheroni, Marco, "La vita a bordeo delle navi", Artigiani e salariati: il mondo del lavoro nell'Italia dei secoli XII-XV. Congreso de Estudios, Pistoia 9-13 octubre 1981. Bolonia, 1984, pp. 155-187.

Villaplana Gisbert, María Victoria, Colección de Documentos para la Historia del Reino de Murcia, vol. XV, Documentación de la minoría de Juan II. La regencia de Don Fernando de Antequera, Murcia, Real Academia Alfonso X el Sabio, 1993.

Wickman, Chris, y Salvador, María Jesús, “Comprender lo cotidiano: antropología social e historia social”, Historia Social, 3 (1989), pp. 115-128.

Wickman, Chris, Framing the early Middle Ages. Europe and the Mediterranean 400800. Oxford, Oxford University Press, 2005. 